\title{
MiR-216a-5p targets TCTN1 to inhibit cell proliferation and induce apoptosis in esophageal squamous cell carcinoma
}

Lixun Chai and Gengpu Yang*

\author{
*Correspondence: yang_Gpu@163. \\ com \\ Department of Thoracic Surgery, \\ Shanxi Dayi Hospital, No. 99 Dragon \\ City Street, Taiyuan 030012, Shanxi \\ Province, China
}

\begin{abstract}
Background: MiR-216a-5p has been reported to be associated with several tumors, including prostate cancer and melanoma. However, its expression level and potential role in esophageal squamous cell carcinoma (ESCC) remain uncertain.

Results: Here, we found that miR-216a-5p expression was significantly down-regulated in clinical ESCC tissues and cells. Functional assays were performed to evaluate the biological effects of miR-216a-5p on cell proliferation and cell apoptosis by CCK-8 assay and flow cytometry in ESCC cell lines, EC9706 and TE-9. The results showed that miR-216a-5p overexpression repressed cell proliferation and induced cell apoptosis. Through bioinformatics prediction and luciferase reporter assay, we revealed that miR-216a-5p could directly target tectonic family member 1 (TCTN1). Moreover, TCTN1 was obviously suppressed by miR-216a-5p overexpression. In addition, TCTN1 expression was significantly increased and inversely correlated with the levels of miR-216a-5p in ESCC tissues. More importantly, down-regulation of TCTN1 imitated, while restoration of TCTN reversed the effects of miR-216a-5p on cell proliferation and apoptosis. At the molecular level, we further found that TCTN1 overexpression reversed the effects of miR-216a-5p transfection on the expression of PCNA, BCl-2 and Bad.

Conclusions: Our results demonstrate that miR-216a-5p might serve as a tumor suppressor in ESCC cells through negatively regulating TCTN1 expression, indicating the possibility that miR-216a-5p and TCTN1 might be attractive targets for ESCC therapeutic intervention.
\end{abstract}

Keywords: ESCC, miR-216a-5p, TCTN1, Proliferation, Apoptosis

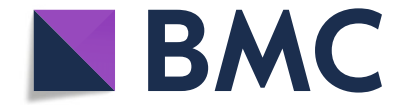

\section{Background}

Esophageal squamous cell carcinoma (ESCC) ranked as the sixth most commonly diagnosed digestive system cancer in the United States in 2017 [1]. It is estimated that there are 16,940 new cases (13,360 in men and 3580 in women) and 15,690 deaths (12,720 in men and 2970 in women) each year in the United States [1]. Several environmental and/ or genetic factors, including obesity, alcohol, and tobacco, were considered to be associated with the etiology of ESCC $[2,3]$. Although some progress has been made in the studies, including changes in diet and physical activity, the survival prognosis still remains poor $[2,4,5]$. It is notable that a deep understanding of the molecular mechanisms

(c) The Author(s). 2019 Open Access This article is distributed under the terms of the Creative Commons Attribution 4.0 International License (http://creativecommons.org/licenses/by/4.0/), which permits unrestricted use, distribution, and reproduction in any medium, provided you give appropriate credit to the original author(s) and the source, provide a link to the Creative Commons license, and indicate if changes were made. The Creative Commons Public Domain Dedication waiver (http://creativecommons.org/ publicdomain/zero/1.0/) applies to the data made available in this article, unless otherwise stated. 
underlying the biological behavior of ESCC will provide important clues for improvement of survival and life quality in patients.

MicroRNAs (miRs) are endogenous small non-coding RNAs that play a variety of diverse roles in biology, including cell cycle progression, proliferation, apoptosis, development and differentiation [6, 7]. By binding to the 3 '-untranslated region (UTR) of their target mRNAs, miRNA can specifically cause protein expression reduction predominantly by destabilizing the target mRNAs and/or by repressing translation [8] [8, 9]. It now appears that a number of miRs are dysregulated in multiple cancers and involved in various pathological and physiological conditions in cancer cells $[9,10]$. Some miRs were found to be upregulated or down-regulated in ESCC, which are thought to play key roles in tumorigenesis and development, such as miR-644a [11], miR-130b [12], and miR-375 [13]. Although the biological role of only a limited number of miR transcripts has been identified in ESCC, many miRs are still unknown.

As a newly identified miRNA encoded by the chromosomal region 2q16.1, miR-216a-5p has received growing attention in recent years [14]. It is reported that miR-216a-5p is down-regulated in pancreatic tissues, and exerts inhibitory effects on proliferation, migration, and invasion in pancreatic ductal adenocarcinoma cells [14]. With regards to lung cancer, the levels of miR-216a-5p are lower in tumor tissues compared with normal lung tissues, and act as an anti-oncogene in lung cancer [15]. Using a synthesized miR-216a-5p inhibitor, decrease of miR-216a-5p inhibited cell viability and motility, thereby depressing tumor growth in renal cell carcinoma cells [16]. However, the role of miR-216a-5p in ESCC remains undefined.

Tectonic family member 1 (TCTN1) involved in the human Hedgehog signaling pathway is a member of tectonic transmembrane proteins [17]. In human endothelial cells, TCTN1 was found to promote endothelial nitric oxide synthase [18]. TCTN1 is also a known protein component of a ciliopathy-associated protein complex and could interact with Mks1, Tmem216, Tmem217, and several other proteins that are associated with ciliopathies to modulate ciliary assembly and trafficking [19]. Interestingly, the primary cilium has an important role in cell-to-cell communication by sensing Hedgehog and Wingless signaling pathways, whose dysregulation affects cancer development, tumorigenesis and prognosis [20-22]. Recent studies revealed that TCTN1 is widely upregulated in various types of human cancer, including gastric cancer [23], colorectal cancer [24], prostate cancer [25], and glioblastoma [26] and acts as an oncogene via promoting proliferation, migration, or inhibiting apoptosis.

In the present study, we aimed to determine levels of miR-216a-5p expression in human ESCC tissues and cell lines. Then, the role of miR-216a-5p in ESCC was investigated by gain-of-function experiments. We focused on TCTN1 as a candidate target of miR-216a$5 p$, as it was predicted by TargetScan. It is certain that understanding the association between miR-216a-5p and TCTN1 could help us develop a useful therapeutic target for ESCC treatments.

\section{Materials and methods}

\section{Clinical specimens}

In total, 25 pairs of human ESCC tissues and matched adjacent tissues ( $>5 \mathrm{~cm}$ away from the tumor margin) were collected from 25 patients who underwent esophagus resection 
without chemotherapy or radiotherapy at the Department of Thoracic Surgery, Shanxi Dayi Hospital (Shanxi, China) between January 2017 and March 2018. All the collected samples were immediately snap-frozen in liquid nitrogen and kept at $-80^{\circ} \mathrm{C}$ for RNA extraction. The basic clinicopathologic characteristics of all patients are listed in Table 1. Written informed consent was obtained from all participants.

\section{Cell culture and transfection}

Human ESCC cell lines (KYSE150, EC9706, KYSE30 and TE-9) and esophageal epithelial cells (HET-1A) were obtained from the Chinese Academy of Science cell bank (Shanghai, China) and cultured in Roswell Park Memorial Institute-1640 medium (RPMI-1640; Invitrogen; Thermo Fisher Scientific, Inc., USA) containing 10\% fetal bovine serum (FBS, Gibco; Thermo Fisher Scientific, Inc.). All cell lines were maintained in a humidified atmosphere with $5 \% \mathrm{CO}_{2}$ at $37^{\circ} \mathrm{C}$.

The synthesized miR-216a-5p mimics (miR-216a-5p), miR-216a-5p inhibitor (inhibitor), negative control (miR-NC), small interfering RNA for TCTN1 (siTCTN1) and its NC (siNC) were purchased from Shanghai GenePharma Co., Ltd. (Shanghai, China). MiR216a-5p overexpression was accomplished by transfecting EC9706 and TE-9 cells with $0.1 \mu \mathrm{M}$ miR-216a-5p mimics or miR-NC for $48 \mathrm{~h}$. MiR-216a-5p silencing was achieved by transfecting HET-1A cells with $0.1 \mu \mathrm{M}$ inhibitor or miR-NC for $48 \mathrm{~h}$. For TCTN1 silencing, EC9706 and TE-9 cells were transfected with siTCTN1 or siNC at a final concentration of $50 \mathrm{nM}$ for $48 \mathrm{~h}$. TCTN1 coding sequences were sub-cloned into pcDNA3.1 (Sangon Biotech, China) to construct the TCTN1 overexpression vector (TCTN1). The empty vector was used as a negative control. In the rescue experiments, EC9706 cells were co-transfected with miR-216a-5p or miR-NC together with TCTN1 or the empty

Table 1 Clinicopathological characteristics of the esophageal squamous cell carcinoma patients $(n=25)$

\begin{tabular}{ll}
\hline Patient characteristics & Cases $(n=25)$ \\
\hline Gender & 16 \\
Male & 9 \\
Female & \\
Age & 19 \\
$<60$ & 6 \\
$\geq 60$ & \\
Tumor size $(\mathrm{cm})$ & 18 \\
$<3$ & 7 \\
$\geq 3$ & \\
TNM stage & 21 \\
I/II & \\
III/IV & 4 \\
Differentiation & \\
Well & 8 \\
Moderate & 12 \\
Poor & 5
\end{tabular}

TNM Tumor node metastasis 
vector. All cell transfections were carried out using Lipofectamine 2000 (Invitrogen, Waltham, MA, USA) in accordance with the manufacturer's instructions.

RNA extraction and quantitative real-time PCR (qRT-PCR)

Total RNA was extracted from tissues or cells using Trizol reagent (Invitrogen, MA, USA), $1 \mu$ g RNA of which was used for reverse transcription using PrimeScript RT Reagent (Takara Bio, Inc.). The expression of miR-216a-5p and TCTN1 was measured using a miScript SYBR-Green PCR kit (Takara Bio, Inc.) and SYBR Premix Ex Taq (Takara Bio, Inc.), respectively. All qRT-PCR reactions were performed on an ABI PRISM 7300 Fast Real-Time PCR System (Ambion, Foster City, CA, USA) with the following thermocycling conditions: $95^{\circ} \mathrm{C}$ for $1 \mathrm{~min}, 40$ cycles of $95^{\circ} \mathrm{C}$ for $15 \mathrm{~s}, 55^{\circ} \mathrm{C}$ for $30 \mathrm{~s}$ and $72^{\circ} \mathrm{C}$ for $30 \mathrm{~s}$. The primer sequences used were as follows: miR-216a-5p, $5^{\prime}$ TGTCGCAAATCTCTGCAGG-3' (forward) and 5'-CAGAGCAGGGTCCGAGGTA3' (reverse); U6, 5'-CTCGCTTCGGCAGCACA-3' (forward), and 5' -ACGCTTCACGAATTTGCGT-3' (reverse); TCTN1， 5'-CCTTTGCGTGAATGTTGTTC-3' (forward), and 5'-AGAGGGACTGGCTGGGTATT-3' (reverse); GAPDH, 5'-GCAC CGTCAAGGCTGAGAAC-3' (forward), and 5' -TGGTGAAGACGCCAGTGGA-3' (reverse). The relative expression of miR-216a-5p or TCTN1 was determined by the $2^{-\Delta \Delta C q}$ method. U6 and GAPDH were used as an internal control for miR-216a-5p and TCTN1, respectively.

\section{Cell proliferation assay}

ESCC cells transfected with miR-216a-5p or siTCTN1 were collected and seeded into 96-well plates at a density of $3 \times 10^{3}$ cells per well. Subsequently, $10 \mu \mathrm{L}$ of CCK- 8 assay solution (Dojindo Laboratories, Kumamoto, Japan) was added to each well at the indicated time points and cells were incubated for $1 \mathrm{~h}$ at $37^{\circ} \mathrm{C}$. Using a microplate reader, cellular proliferation was measured by detecting the absorbance at $450 \mathrm{~nm}$.

\section{Flow cytometry assay}

The cell apoptosis were assessed by a flow cytometer (BD FACSCalibur; BD Biosciences) with double Annexin V/PI staining (Invitrogen). In brief, approximately $3 \times 10^{5}$ transfected cells were harvested from a 6-well plate by centrifugation and mixed with $500 \mu \mathrm{l}$ of $1 \mathrm{X}$ binding buffer, followed by staining with $5 \mu \mathrm{l}$ of FITC-Annexin V and propidium iodide (PI). The early apoptotic (Annexin V+/PI-) and late apoptotic (Annexin $\mathrm{V}+/ \mathrm{PI}+$ ) cells were analyzed by flow cytometry and the total apoptotic rate was calculated in each group.

\section{Dual luciferase reporter assay}

TargetScan (http://www.targetscan.org/vert_71/) was applied to predict the putative targets of miR-216a-5p. To confirm whether miR-216a-5p directly targets the 3 '-UTR of TCTN1, the wild-type or mutant 3'-UTR of TCTN1 was amplified and cloned into the vector psiCHECK-2 to construct luciferase reporter plasmids (WT TCTN1 or MUT TCTN1, respectively). For the luciferase reporter assay, $293 \mathrm{~T}$ cells $\left(1 \times 10^{4} /\right.$ well $)$ were cotransfected with WT TCTN1 or MUT TCTN1 together with miR-216a-5p or miR-NC using Lipofectamine 2000 according to the manufacturer's instructions. After $48 \mathrm{~h}$ of transfection, the Renilla and firefly luciferase activity was detected using the Dual- 
Luciferase Reporter Assay kit (Promega Corp., Madison, WI, USA). Data were expressed as the ratio of Renilla luciferase activity normalized to Renilla luciferase activity.

\section{Western blotting analysis}

Total proteins were extracted from cells using lysis buffer (Beyotime Institute of Biotechnology, Haimen, China) and quantified according to the protocol of a BCA Protein Assay Kit (Thermo Fisher Scientific). Equal amounts of protein samples were subjected to separation on 10\% SDS-PAGE gels and transferred onto polyvinylidene fluoride (PVDF) membranes (Millipore, Billerica, MA, USA). Then, the membranes were blocked with 5\% skim milk for $2 \mathrm{~h}$ at room temperature, followed by incubation with primary antibodies against TCTN1, PCNA, Bcl-2, Bad and GAPDH overnight at $4{ }^{\circ} \mathrm{C}$. After incubation with horseradish peroxidase-conjugated secondary antibody for $2 \mathrm{~h}$, the membranes were visualized using an ECL kit (Beyotime Institute of Biotechnology, Beijing, China).

\section{Statistical analysis}

All statistical analyses were performed using GraphPad Prism 6.0 (GraphPad Software, Inc., La Jolla, CA, USA) and data were expressed as the mean \pm standard deviation (SD). The correlation between miR-216a-5p expression and TCTN1 mRNA expression levels was examined using Pearson's correlation analysis. Comparisons between two groups were made using Student's t-test. Differences among multiple groups were assessed using one-way analysis of variance followed by Tukey's test. The value of $p<0.05$ was considered to be statistically significant.

\section{Results}

MiR-216a-5p was significantly downregulated in ESCC tissues and cell lines

To explore the functional role of miR-216a-5p in ESCC, the expression levels of miR216a-5p were determined in ESCC tissues and the adjacent non-tumor tissues by qRTPCR. As illustrated in Fig. 1a, miR-216a-5p was significantly downregulated in 25 pairs
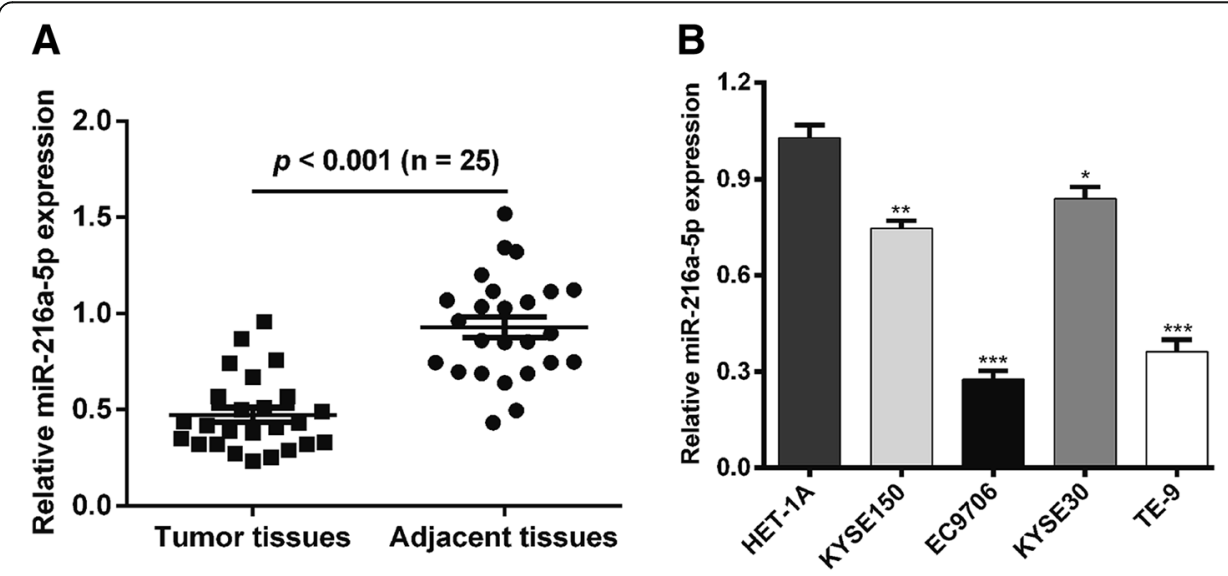

Fig. 1 MiR-216a-5p was significantly down-regulated in ESCC tissues and cell lines. a MiR-216a-5p expression levels in 25 pairs of ESCC tissues compared with matched adjacent normal tissues were determined using qRT-PCR. $\mathbf{b}$ MiR-216a-5p expression in four ESCC cell lines and normal esophageal epithelial HET-1A cells was measured using qRT-PCR. ${ }^{*} p<0.05,{ }^{* *} p<0.01,{ }^{* * *} p<0.001$ vs. normal group; ESCC, esophageal squamous cell carcinoma; $q R T-P C R$, quantitative real-time PCR 
of ESCC tissues in comparison with matched adjacent tissues. The miR-216a-5p expression levels were also measured in four human ESCC cell lines: KYSE150, EC9706, KYSE30 and TE-9. The results revealed that miR-216a-5p was also markedly decreased in all four ESCC cell liens compared with those in normal esophageal epithelial HET1A cells (Fig. 1b). Among the four ESCC cell lines, EC9706 and TE-9 expressed the lowest miR-216a-5p levels and were thus selected for further analyses.

\section{MiR-216a-5p suppressed ESCC cell proliferation and promoted cell apoptosis}

We then investigated the biological function of miR-216a-5p by transfecting miR-216a-5p mimics or miR-NC in EC9706 and TE-9 cells, which exhibited low expression of miR-216a5p. Subsequent to transfection, qRT-PCR confirmed that miR-216a-5p was significantly increased in EC9706 and TE-9 cells after miR-216a-5p mimic transfection (Fig. 2a, $p<0.001$ ). The results of CCK- 8 assay revealed that miR-216-5p overexpression dramatically suppressed the proliferation of EC9706 and TE-9 cells compared with the miR-NC group (Fig. $2 \mathrm{~b}, p<$ 0.001). Moreover, cell apoptosis assays were performed in the miR-216a-5p transfected cells by flow cytometry. As shown in Fig. 2c, the overall apoptotic percentage (EC9706: 13.54\% \pm $0.63 \%$ vs. $23.38 \% \pm 0.67 \%$; TE- 9 : $11.15 \% \pm 0.54 \%$ vs. $23.39 \% \pm 0.84 \%$ ) in the miR-216a-5p group was significantly higher than that in the miR-NC group. These results demonstrated that miR-216a-5p might act as a tumor suppressor in ESCC by inhibiting cell proliferation.

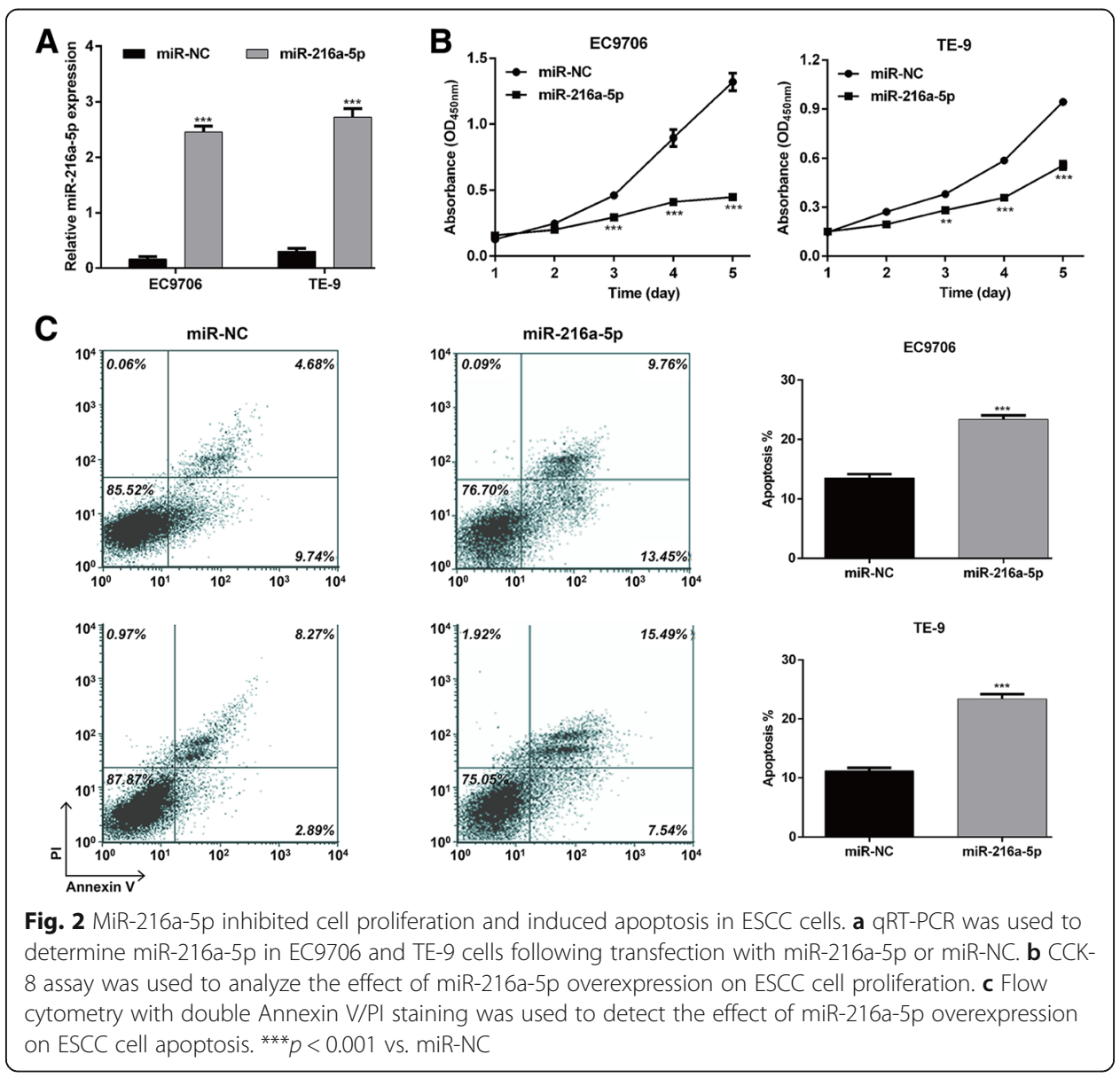




\section{TCTN1 is a direct target of miR-216a-5p in ESCC}

To reveal the molecular mechanisms underlying the roles of miR-216a-5p on ESCC cell proliferation and apoptosis, online bioinformatics analysis was performed to predict the potential target genes of miR-216a-5p. As presented in Fig. 3a, the 3'-UTR of TCTN1 was found to contain a complementary region of miR-216-5p seed sequences, indicating that TCTN1 might be a potential target gene of miR-216-5p. Subsequently, a luciferase report assay was performed to examine whether miR-216a-5p may directly target TCTN1. The results revealed that introduction of miR-216a-5p to $293 \mathrm{~T}$ cells could significantly reduce the luciferase activity of the reporter plasmid with WT TCTN1 but did not obviously change the expression of a reporter fused to MUT TCTN1 (Fig. 3b, $p<0.001$ ). Moreover, qRTPCR (Fig. 3c, $p<0.001$ ) and western blot (Fig. 3d) analyses further confirmed that miR216a-5p overexpression reduced TCTN1 expression at mRNA and protein levels in both EC9706 and TE-9 cells. In addition, we found that silencing miR-216a-5p in the normal esophageal epithelial cell line HET-1A by inhibitor upregulated the expression of TCTN1 (Fig. 3e). Next, we measured mRNA expressions of TCTN1 in ESCC tissues and the matched adjacent specimens. As shown in Fig. 3f, the expression of TCTN1 was significantly higher in ESCC tissues compared with adjacent normal tissues. Pearson's correlation analysis further demonstrated that the expression levels of miR-216a-5p and TCTN1 were inversely correlated in ESCC tissues (Fig. 3g, $p=0.0425$ ). These data implied that TCTN1 might play important roles in ESCC, which was directly targeted by miR-216a-5p.

\section{TCTN1 knockdown inhibited cell proliferation and induced apoptosis in ESCC}

We next investigated whether miR-216a-5p affected cell proliferation and apoptosis of ESCC cells by targeting TCTN1. Both EC9706 and TE-9 cells were transfected with siTCTN1 to decrease the expression of TCTN1, as confirmed by qRT-PCR (Fig. 4a, $p<$ 0.001 ) and western blot analysis (Fig. $4 \mathrm{~b}$ ). The CCK-8 assay revealed that the cell

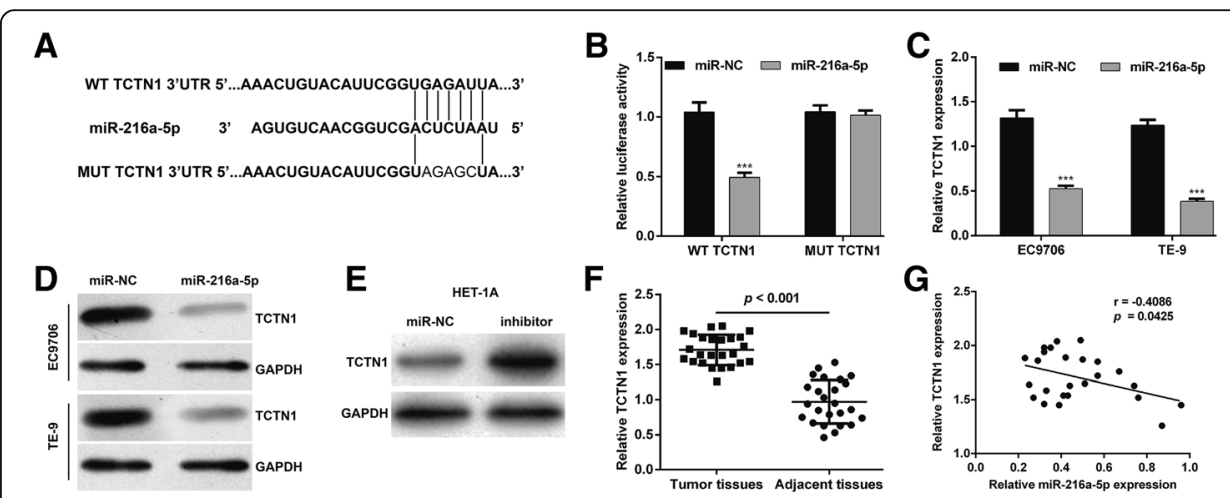

Fig. 3 TCTN1 was a direct target of miR-216a-5p. a Putative binding sites of 216a-5p within the $3^{\prime}-U T R$ region of TCTN1 mRNA, and the sequences of wild-type and mutant-type vector. $\mathbf{b}$ The relative luciferase activities were inhibited in 293 T cells co-transfected with wild-type TCTN1 3'-UTR vector and miR-216a-5p, not with the mutant-type vector. Firefly luciferase activity was normalized to Renilla luciferase. Data are presented as the mean value \pm SD from triplicate experiments. ${ }^{* *} p<0.001$ vs. miR-NC; $\mathbf{c}$ mRNA and $\mathbf{d}$ protein levels of TCTN1 were detected by qRT-PCR and western blot in EC9706 and TE-9 cells transfected with miR-216a-5p or miR-NC. e The protein level of TCTN1 was determined by western blot in HET-1A cells transfected with miR-216a-5p inhibitor or miR-NC. $\mathbf{f}$ Relative expression levels of TCTN1 mRNA in ESCC tissues and adjacent tissues were detected by qRT-PCR. $\mathbf{g}$ Pearson's correlation analysis for the relationship between miR-216a-5p levels and TCTN1 mRNA levels in ESCC tissues 


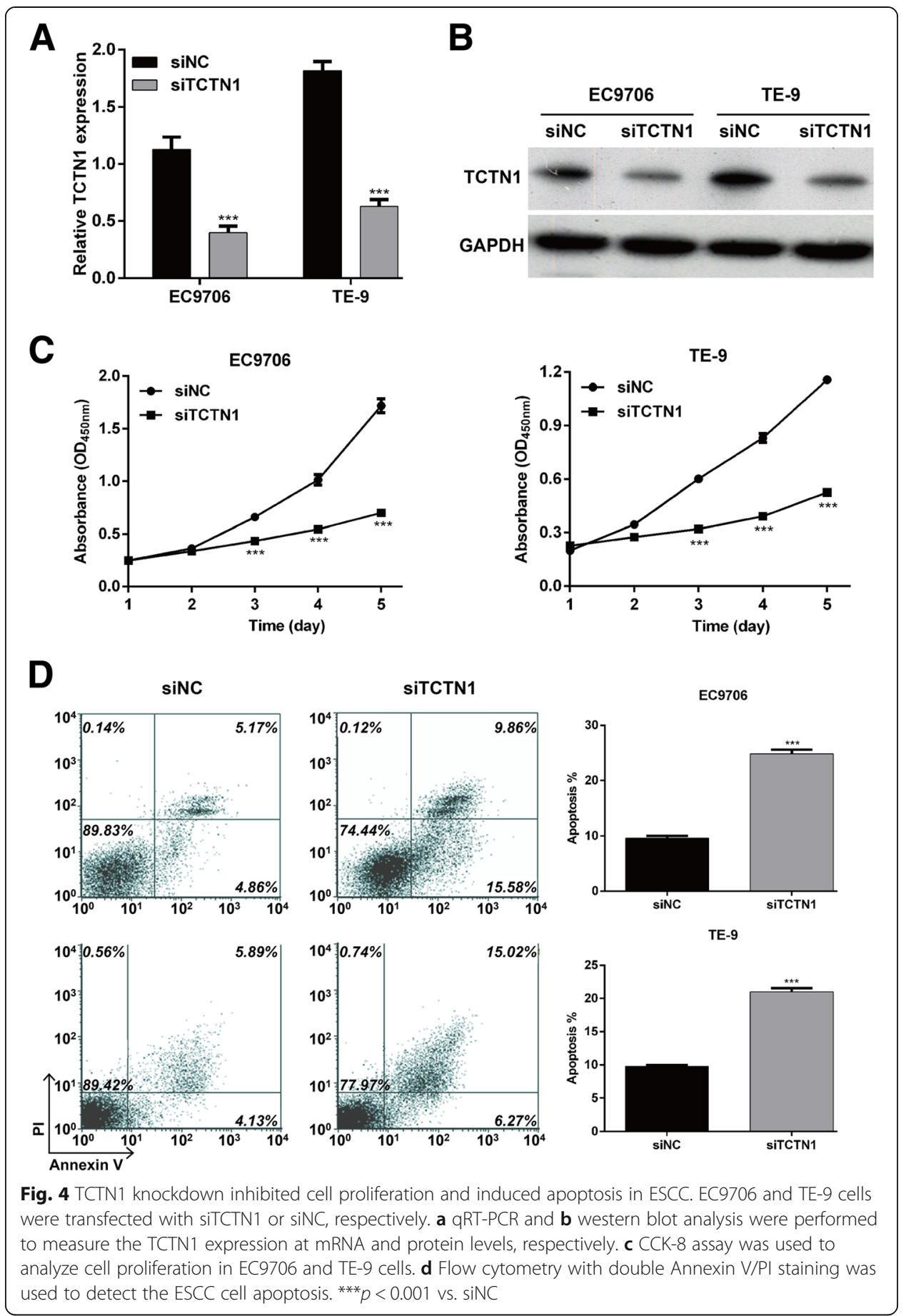

proliferation rate was remarkably impaired in siTCTN1 transfected EC9706 and TE-9 cells compared with siNC groups (Fig. 4c, $p<0.001$ ). Consistently, TCTN1 knockdown significantly increased the overall apoptotic percentage from $9.58 \% \pm 0.44$ to $24.84 \% \pm$ $0.74 \%$ in EC9706 and from $9.79 \% \pm 0.21$ to $20.98 \% \pm 0.58 \%$ in TE-9 cells (Fig. $4 \mathrm{~d}, p<$ 0.001). These data indicated that TCTN1 down-regulation might be the mechanism of the miR-216a-5p induced decreased proliferation and increased apoptosis of ESCC cells. 

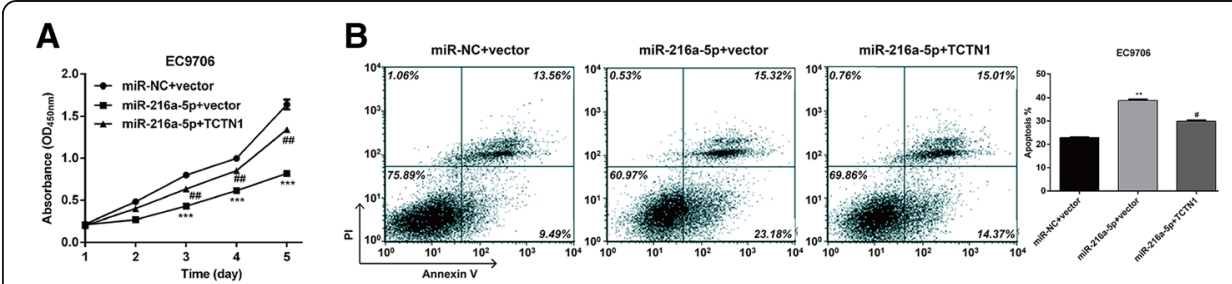

Fig. 5 Addition of TCTN1 reversed miR-216a-5p-mediated effects on cell proliferation and apoptosis. EC9706 cells were co-transfected with miR-216a-5p mimic/miR-NC and with TCTN1 overexpression plasmid/ empty vector. a CCK-8 assay was used to analyze cell proliferation. b Flow cytometry with double Annexin V/PI staining was used to detect cell apoptosis. ${ }^{* *} p<0.01,{ }^{* * *} p<0.001$ vs. siNC+vector; $\# p<0.05$, \#\#p 0.01 vs. miR-216a-5p + vector

Restoration of TCTN1 abolished the effects of miR-216a-5p on cell proliferation and apoptosis

To further explore whether TCTN1 was required for the miR-216a-5p-mediated effects on cell proliferation and apoptosis, we next performed rescue experiments by transfecting an overexpression plasmid of TCTN1 (pcDNA3.1-TCTN1) into EC9706 cells treated with miR-216a-5p. As expected, the decreased cell

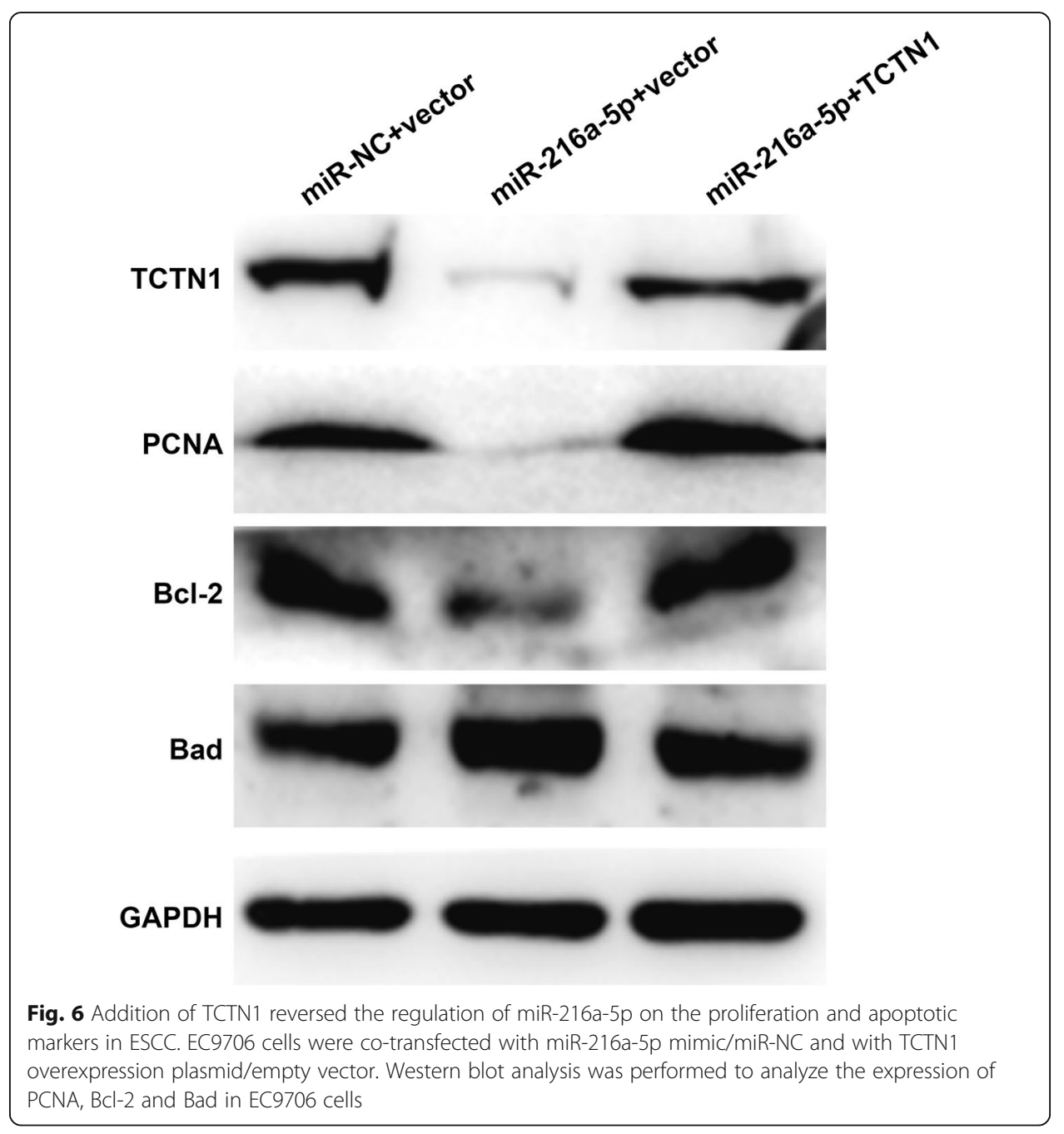


proliferation and increased cell apoptosis by miR-216a-5p were partially abolished by overexpressing TCTN1 in EC9706 cells, as determined by CCK-8 (Fig. 5a) and flow cytometry analysis (Fig. 5b), respectively. Furthermore, we detected the expression alterations of several markers. As shown in Fig. 6, miR-216a-5p overexpression obviously down-regulated TCTN1 expression, leading to a reduction of PCNA, anti-apoptotic protein $\mathrm{Bcl}-2$ and elevation of pro-apoptotic protein Bad. However, TCTN1 overexpression reversed the effects of miR-216a-5p transfection on the expression of TCTN1, PCNA, Bcl-2 and Bad. These findings further demonstrated that TCTN1 might be a key regulator in the miR-216a-5p-mediated cell proliferation and apoptosis in ESCC cells.

\section{Discussion}

In the present study, we found that overexpression of miR-216a-5p in ESCC cells obviously suppressed cell proliferation and induced apoptosis. Meaningfully, we could link changes in cell growth and survival to the direct targeting of TCTN1, which participated in a diverse range of developmental procedures [27].

The miR-216a-5p gene was previously identified only in pancreatic ductal adenocarcinoma [14] and renal cell carcinoma. Interestingly, miR-216a-5p has dual roles in regulating cancer cell development and tumorigenesis, which can inhibit pancreatic ductal adenocarcinoma cell proliferation, migration and invasion [25]. By contrast, Chen et al. [16] pointed to the oncogenetic role of miR-216a-5p in renal cancer. Considering that the role of miR216a-5p is distinct in different tumor types, the expression of miR-216a-5p was first determined individually in ESCC tissues and cell lines. Here, we found that miR-216a-5p was significantly down-regulated in ESCC tissues and cell lines. EC9706 and TE-9 cell lines were chosen for subsequent loss-of-function analysis. The results showed that proliferation in ESCC cells can be blocked and apoptosis can be stimulated by miR-216a-5p, suggesting an anti-tumor role of miR-216a-5p in ESCC.

Degradation of miR-216a-5p targets is the dominant effect of miR-216a-5p in cancer, including (i) inhibition of hexokinase-2 in uveal melanoma [28] and (ii) downregulation of matrix metalloproteinase 16 in lung cancer [15]. In particular, TCTN1 was regarded as a possible target gene of miR-216a-5p by using TargetScan. Moreover, luciferase reporter assay confirmed this prediction as the relative luciferase activities were suppressed in $293 \mathrm{~T}$ cells co-transfected with WT TCTN1 3'-UTR vector and miR-216a-5p, compared with mutant-type vector. Generally, the biological behaviors of ESCC cells with knockdown of TCTN1 tended to imitate these cells with overexpression of miR-216a-5p. Mechanistically, we suggest that miR-216a-5p exerts its tumor suppressive role via targeting TCTN1. Notably, overexpression of miR-216a-5p could down-regulate the expression of PCNA and pro-apoptotic Bad, but up-regulate the expression of anti-apoptotic Bcl-2, which was reversed by TCTN1 overexpression.

Numerous growth pathways contribute to cell proliferation in cancer cells [29]. PCNA, a ring-shaped protein, is also known as a critical component of the DNA machinery responsible for DNA replication and genomic stability [30, 31]. It exerts biological effects on DNA damage repair and DNA proliferation through binding to the flap endonuclease 1 (FEN-1) and xeroderma pigmentosum (XP) G, and facilitates resynthesis of a new DNA fragment [32, 33]. In recent years, many studies have provided a deeper comprehension of PCNA as a factor in miRNA-mediated regulation of cellular 
development, growth and maintenance. MiR-363-3p has been reported to suppress the specific target gene PCNA to exert an anti-proliferation effect on lung cancer cells [34]. The anti-tumor activity of miR-149 in glioma cells was found to be correlated with low-expression of PCNA, p-AKT1, cyclin D1, and MMP-2 [35]. In this study, we suggest that, with the enhanced expression of miR-216a-5p, signaling to proliferation can be inactivated due to the down-regulated expression of PCNA.

Beneath the complexity and heterogeneity of each cancer lies survival events that have propelled the cancer cells escaped from pathognomonic cellular changes [36]. Accumulating evidence indicates that the processes of neoplastic transformation, development and tumorigenesis involve abnormalities in apoptosis signaling pathways [37]. In our present study, overexpressing miR-216a-5p ESCC cells showed a significant decrease in PCNA and Bcl-2 and an increase in Bad. Bcl-2, an inner mitochondrial transmembrane protein, is known to be a key anti-apoptotic regulator [38]. The sensitizer $\mathrm{BH}-3$-only protein Bad could induce apoptosis by binding and inactivating $\mathrm{Bcl}-2$ and anti-apoptotic Bcl-xL [39, 40]. Current understanding of molecular ESCC apoptosis suggests that up-regulation of Bcl-2 and down-regulation of Bad caused by TCTN1 overexpression are major mechanisms of miR-216a-5p-mediated apoptosis.

These findings lead to the interesting conclusion that inhibition of ESCC cell carcinogenesis occurred in response to miR-216a-5p targeting TCTN1 characterized by antiproliferative activity and induction of apoptosis. In tumor cells, the expression of TCTN1 has been demonstrated to be overexpressed in many different cancer types [23, 26, 41]. Silencing of TCTN1 was suggested to induce human thyroid cancer cell apoptosis through over-expression of cleaved caspase-3 and PARP and repression of Bcl-2 [41]. Silencing of TCTN1 by lentivirus-mediated RNA interference in gastric cancer and pancreatic cancer cells and reduction of proliferation were observed, suggesting that the knockdown of TCTN1 is sufficient to inhibit cell viability [23, 42]. In this study, the expression levels of TCTN1 were up-regulated in ESCC tissues compared with adjacent tissues. Further data confirmed that miR-216a-5p suppressed ESCC cell proliferation at least partially by down-regulating TCTN1 expression.

\section{Conclusions}

In conclusion, our findings identify the miR-216a-5p/TCTN1 axis as a mechanism of miR216a-5p-mediated inhibition of ESCC cell proliferation and induction of apoptosis, with potentially important implications for development of ESCC therapy.

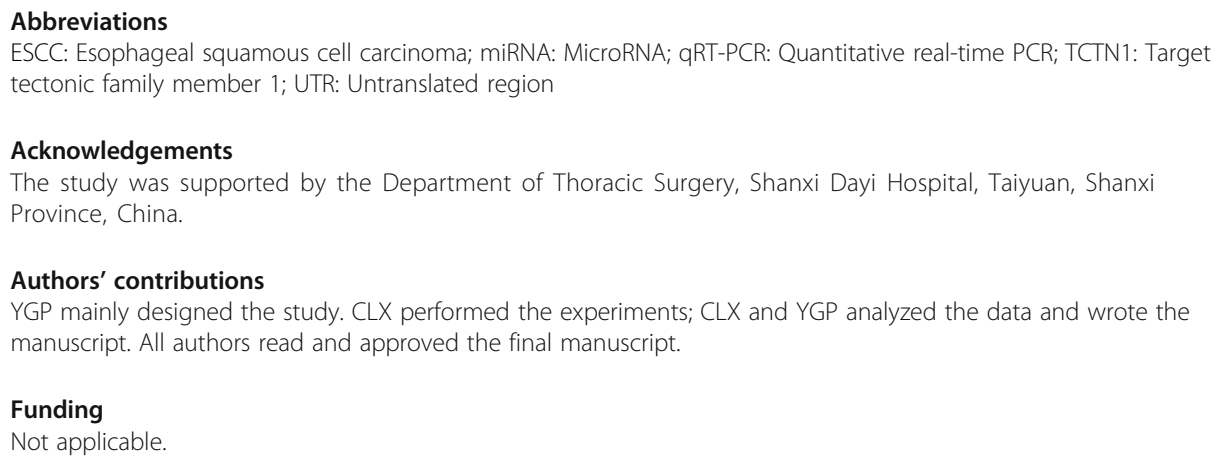




\section{Ethics approval and consent to participate}

This study involving human participants was approved by the ethics committee of Shanxi Dayi Hospital (SDH-A-2017035, Date: 2017.1.16; Shanxi, China). All the tissue samples were collected with written informed consent in accordance with the Declaration of Helsinki.

\section{Consent for publication}

Not applicable.

\section{Competing interests}

The authors declare that they have no competing interests.

Received: 5 November 2018 Accepted: 4 June 2019

Published online: 28 June 2019

\section{References}

1. Siegel RL, Miller KD, Jemal A. Cancer statistics, 2017. CA Cancer J Clin. 2017;67:7-30. https://doi.org/10.3322/caac.21387.

2. Lento A, Long A, Giroux V, Tang Q, Sammons M, Klein-Szanto A, Berger S, Rustgi A, Lento A, Long A. Abstract 2578: investigating the role of mutant p53 in esophageal squamous cell carcinoma. Cancer Res. 2017;77:2578.

3. Prabhu A, Obi KO, Rubenstein $\mathrm{JH}$. The synergistic effects of alcohol and tobacco consumption on the risk of esophageal squamous cell carcinoma: a meta-analysis. Am J Gastroenterol. 2014;109:822-7. https://doi.org/10.1038/ajg.2014.71.

4. Stoner GD, Gupta A. Etiology and chemoprevention of esophageal squamous cell carcinoma. Carcinogenesis. 2001;22: 1737-46.

5. Baba Y, Yoshida N, Shigaki H, Iwatsuki M, Miyamoto Y, Sakamoto Y, Watanabe M, Baba H. Prognostic impact of postoperative complications in 502 patients with surgically resected esophageal squamous cell carcinoma: a retrospective single-institution study. Ann Surg. 2016;264:305-11. https://doi.org/10.1097/SLA.0000000000001510.

6. Acunzo M, Romano G, Wernicke D, Croce CM. MicroRNA and cancer--a brief overview. Adv Biol Regul. 2015;57:1-9. https://doi.org/10.1016/j.jbior.2014.09.013.

7. Tufekci KU, Meuwissen RL, Genc S. The role of microRNAs in biological processes. Methods Mol Biol. 2014;1107:15-31. https://doi.org/10.1007/978-1-62703-748-8_2

8. Valinezhad Orang A, Safaralizadeh R, Kazemzadeh-Bavili M. Mechanisms of miRNA-mediated gene regulation from common downregulation to mRNA-specific upregulation. Int J Genomics. 2014:2014:970607. https://doi.org/10.1155/2014/970607.

9. Xie B, Ding Q, Han H, Wu D. miRCancer: a microRNA-cancer association database constructed by text mining on literature. Bioinformatics. 2013;29:638-44. https://doi.org/10.1093/bioinformatics/btt014.

10. Xie Y, Murray-Stewart T, Wang Y, Yu F, Li J, Marton L, Casero RA Jr, Oupicky D. Self-immolative nanoparticles for simultaneous delivery of microRNA and targeting of polyamine metabolism in combination cancer therapy. J Control Release. 2017;246:110-9. https://doi.org/10.1016/j.jconrel.2016.12.017.

11. Zhang JX, Chen ZH, Xu Y, Chen JW, Weng HW, Yun M, Zheng ZS, Chen C, Wu BL, Li EM, et al. Downregulation of MicroRNA-644a promotes esophageal squamous cell carcinoma aggressiveness and stem cell-like phenotype via dysregulation of PITX2. Clin Cancer Res. 2017;23:298-310. https://doi.org/10.1158/1078-0432.CCR-16-0414.

12. Yu T, Cao R, Li S, Fu M, Ren L, Chen W, Zhu H, Zhan Q, Shi R. MiR-130b plays an oncogenic role by repressing PTEN expression in esophageal squamous cell carcinoma cells. BMC Cancer. 2015;15:29. https://doi.org/10.1186/ s12885-015-1031-5.

13. Osako Y, Seki N, Kita Y, Yonemori K, Koshizuka K, Kurozumi A, Omoto I, Sasaki K, Uchikado Y, Kurahara H, et al. Regulation of MMP13 by antitumor microRNA-375 markedly inhibits cancer cell migration and invasion in esophageal squamous cell carcinoma. Int J Oncol. 2016;49:2255-64. https://doi.org/10.3892/ijo.2016.3745.

14. Yonemori K, Seki N, Idichi T, Kurahara H, Osako Y, Koshizuka K, Arai T, Okato A, Kita Y, Arigami T, et al. The microRNA expression signature of pancreatic ductal adenocarcinoma by RNA sequencing: anti-tumour functions of the microRNA-216 cluster. Oncotarget. 2017;8:70097-115. https://doi.org/10.18632/oncotarget.19591.

15. Ning AN, Hongmin LI, Ruilian YU, Luo S, Zhang M, Lan H, Oncology DO. miR-216a-5p inhibits invasion ability in human lung cancer cells by down-regulation of MMP16 expression. China Oncol. 2015. http://xueshu.baidu.com/usercenter/ paper/show?paperid=80ddf4e035349121059862ce4cc3a590\&site=xueshu_se.

16. Chen P, Quan J, Jin L, Lin C, Xu W, Xu J, Guan X, Chen Z, Ni L, Yang S, et al. miR-216a-5p acts as an oncogene in renal cell carcinoma. Exp Ther Med. 2018;15:4039-46. https://doi.org/10.3892/etm.2018.5881.

17. Szymanska K, Hartill VL, Johnson CA. Unraveling the genetics of Joubert and Meckel-Gruber syndromes. J Pediatr Genet. 2014;3:65-78. https://doi.org/10.3233/PGE-14090.

18. Jamaluddin M, Liang Z, L J, Yao Q, Chen C. Tectonic1, a new hedgehog signaling molecule, upregulates endothelial nitric oxide synthase in human endothelial cells. J Surg Res. 2013;179:331. https://doi.org/10.1016/j. jss.2012.10.673.

19. Garcia-Gonzalo FR, Corbit KC, Sirerol-Piquer MS, Ramaswami G, Otto EA, Noriega TR, Seol AD, Robinson JF, Bennett CL, Josifova DJ, et al. A transition zone complex regulates mammalian ciliogenesis and ciliary membrane composition. Nat Genet. 2011:43:776-84. https://doi.org/10.1038/ng.891.

20. Berbari NF, O'Connor AK, Haycraft CJ, Yoder BK. The primary cilium as a complex signaling center. Curr Biol. 2009;19: R526-35. https://doi.org/10.1016/j.cub.2009.05.025.

21. Stewart DJ, Chang DW, Ye Y, Spitz M, Lu C, Shu X, Wampfler JA, Marks RS, Garces Yl, Yang P, Wu X. Wnt signaling pathway pharmacogenetics in non-small cell lung cancer. Pharmacogenomics J. 2014;14:509-22. https:// doi.org/10.1038/tpj.2014.21.

22. Taipale J, Beachy PA. The hedgehog and Wnt signalling pathways in cancer. Nature. 2001:411:349-54. https://doi. org/10.1038/35077219.

23. Wang $X, Y u Q$, Zhang $Y$, Ling Z, Yu P. Tectonic 1 accelerates gastric cancer cell proliferation and cell cycle progression in vitro. Mol Med Rep. 2015;12:5897-902. https://doi.org/10.3892/mmr.2015.4177. 
24. Dai X, Dong M, Yu H, Xie Y, Yu Y, Cao Y, Kong Z, Zhou B, Xu Y, Yang T, Li K. Knockdown of TCTN1 strongly decreases growth of human Colon Cancer cells. Med Sci Monit. 2017;23:452-61.

25. Wang Z, Gao Y, Liu Y, Chen J, Wang J, Gan S, Xu D, Cui X. Tectonic1 contributes to the growth and migration of prostate cancer cells in vitro. Int J Mol Med. 2015;36:931-8. https://doi.org/10.3892/ijmm.2015.2313.

26. Li J, Wang H, Hang C, Fan Y, Ma C, Pan Y. Lentivirus-mediated knockdown of TCTN1 inhibits glioma cell proliferation. Appl Biochem Biotechnol. 2015;176:13-21. https://doi.org/10.1007/s12010-015-1498-1.

27. Meng D, Chen Y, Zhao Y, Wang J, Yun D, Yang S, Chen J, Chen H, Lu D. Expression and prognostic significance of TCTN1 in human glioblastoma. J Transl Med. 2014;12:288. https://doi.org/10.1186/s12967-014-0288-9.

28. Liu Y, Huo Y, Wang D, Tai Y, Li J, Pang D, Zhang Y, Zhao W, Du N, Huang Y. MiR-216a-5p/hexokinase 2 axis regulates uveal melanoma growth through modulation of Warburg effect. Biochem Biophys Res Commun. 2018;501:885-92. https://doi.org/10.1016/j.bbrc.2018.05.069.

29. Evan Gl, Vousden KH. Proliferation, cell cycle and apoptosis in cancer. Nature. 2001;411:342-8. https:/doi.org/10.1038/ 35077213.

30. Zhao H, Chen MS, Lo YH, Waltz SE, Wang J, Ho PC, Vasiliauskas J, Plattner R, Wang YL, Wang SC. The Ron receptor tyrosine kinase activates C-Abl to promote cell proliferation through tyrosine phosphorylation of PCNA in breast cancer. Oncogene. 2014;33:1429-37. https://doi.org/10.1038/onc.2013.84.

31. Funk JO, Waga S, Harry JB, Espling E, Stillman B, Galloway DA. Inhibition of CDK activity and PCNA-dependent DNA replication by p21 is blocked by interaction with the HPV-16 E7 oncoprotein. Genes Dev. 1997;11:2090-100.

32. Gary R, Ludwig DL, Cornelius HL, Maclnnes MA, Park MS. The DNA repair endonuclease XPG binds to proliferating cell nuclear antigen (PCNA) and shares sequence elements with the PCNA-binding regions of FEN-1 and cyclin-dependent kinase inhibitor p21. J Biol Chem. 1997;272:24522-9.

33. Becker JR, Gallo D, Leung W, Croissant T, Thu YM, Nguyen HD, Starr TK, Brown GW, Bielinsky AK. Flap endonuclease overexpression drives genome instability and DNA damage hypersensitivity in a PCNA-dependent manner. Nucleic Acids Res. 2018;46:5634-50. https://doi.org/10.1093/nar/gky313.

34. Wang Y, Chen T, Huang H, Jiang Y, Yang L, Lin Z, He H, Liu T, Wu B, Chen J, et al. miR-363-3p inhibits tumor growth by targeting PCNA in lung adenocarcinoma. Oncotarget. 2017;8:20133-44. https://doi.org/10.18632/oncotarget.15448.

35. Pan SJ, Zhan SK, Pei BG, Sun QF, Bian LG, Sun BM. MicroRNA-149 inhibits proliferation and invasion of glioma cells via blockade of AKT1 signaling. Int J Immunopathol Pharmacol. 2012;25:871-81. https:/doi.org/10.1177/039463201202500405.

36. Scatena R. Mitochondria and cancer: a growing role in apoptosis, cancer cell metabolism and dedifferentiation. Adv Exp Med Biol. 2012;942:287-308. https://doi.org/10.1007/978-94-007-2869-1_13.

37. Havrilesky L, Elbendary A, Hurteau JA, Whitaker RS, Rodriguez GC, Berchuck A. Chemotherapy-induced apoptosis in epithelial ovarian cancers. Obstet Gynecol. 1995:85:1007-10.

38. Sun C, Liu Z, Li S, Yang C, Xue R, Xi Y, Wang L, Wang S, He Q, Huang J, et al. Down-regulation of c-met and Bcl2 by microRNA-206, activates apoptosis, and inhibits tumor cell proliferation, migration and colony formation. Oncotarget. 2015;6:25533-74. https://doi.org/10.18632/oncotarget.4575.

39. Lam LT, Lin X, Faivre EJ, Yang Z, Huang X, Wilcox DM, Bellin RJ, Jin S, Tahir SK, Mitten M, et al. Vulnerability of small-cell lung Cancer to apoptosis induced by the combination of BET Bromodomain proteins and BCL2 inhibitors. Mol Cancer Ther. 2017;16:1511-20. https://doi.org/10.1158/1535-7163.MCT-16-0459.

40. Karpel-Massler G, Ishida CT, Bianchetti E, Shu C, Perez-Lorenzo R, Horst B, Banu M, Roth KA, Bruce JN, Canoll P, et al. Inhibition of mitochondrial matrix chaperones and Antiapoptotic BCl-2 family proteins empower antitumor therapeutic responses. Cancer Res. 2017;77:3513-26. https://doi.org/10.1158/0008-5472.CAN-16-3424.

41. Xu P, Xia X, Yang Z, Tian Y, Di J, Guo M. Silencing of TCTN1 inhibits proliferation, induces cell cycle arrest and apoptosis in human thyroid cancer. Exp Ther Med. 2017;14:3720-6. https://doi.org/10.3892/etm.2017.4940.

42. Zhao $S$, Chen $X$, Wan M, Jiang X, Li C, Cui Y, Kang P. Tectonic 1 is a key regulator of cell proliferation in pancreatic Cancer. Cancer Biother Radiopharm. 2016;31:7-13. https://doi.org/10.1089/cbr.2014.1778.

\section{Publisher's Note}

Springer Nature remains neutral with regard to jurisdictional claims in published maps and institutional affiliations.

Ready to submit your research? Choose BMC and benefit from:
- fast, convenient online submission
- thorough peer review by experienced researchers in your field
- rapid publication on acceptance
- support for research data, including large and complex data types
- gold Open Access which fosters wider collaboration and increased citations
- maximum visibility for your research: over 100M website views per year
At BMC, research is always in progress.
Learn more biomedcentral.com/submissions

